\title{
How to be sure: sensory exploration and empirical certainty
}

Post-print/Accepted manuscript

Mohan Matthen

Matthen, M. (2014), How to Be Sure: Sensory Exploration and Empirical Certainty. Philosophy and Phenomenological Research, 88: 38-69. doi:10.1111/j.1933-1592.2011.00548.x

This is the peer reviewed version of the following article: Matthen, M. (2014), How to Be Sure: Sensory Exploration and Empirical Certainty. Philosophy and Phenomenological Research, 88: 38-69, which has been published in final form at http://dx.doi.org/10.1111/j.1933-1592.2011.00548.x This article may be used for non-commercial purposes in accordance with Wiley Terms and Conditions for Self-Archiving.

\section{HOW TO CITE TSPACE ITEMS}

Always cite the published version, so the author(s) will receive recognition through services that track citation counts, e.g. Scopus. If you need to cite the page number of the TSpace version (original manuscript or accepted manuscript) because you cannot access the published version, then cite the TSpace version in addition to the published version using the permanent URI (handle) found on the record page. 


\section{Mohan Matthen \\ University of Toronto}

\section{HOW TO BE SURE: SENSORY EXPLORATION AND EMPIRICAL CERTAINTY*}

The senses can completely dispel rational grounds for a certain kind of doubt, which I shall call empirical doubt, but they cannot dispel another kind, sceptical doubt. In this paper, I elaborate this claim and argue in its support.

In the first part of the paper (sections I-III), I describe and discuss a kind of knowledge-gathering activity that I call sensory exploration, and motivate the notion that it eliminates grounds for empirical doubt. Sensory exploration is a distinctive source of knowledge, hitherto unrecognized by philosophers. It relies (of course) on the senses; I'll argue, further, that it does not rely on background non-sensory beliefs. It involves sensory experience (which has been discussed extensively in the philosophical literature), but, as I shall show, it cannot be reduced to sensory experience-both because it involves something more, and because its epistemic authority does not rest on that of experience alone.

In the second part of the paper (sections IV-VII), I discuss the epistemic warrant that sensory exploration provides. The position I espouse in this part of the paper somewhat resembles that of G. E. Moore (1959), who thought that clear deliverances of the senses (e.g., "I am standing up, and not either sitting or lying down") are immune from all doubt. My position is not, however, quite as forward as

${ }^{*}$ I have delivered this paper to a number of audiences, and discussion has been enormously useful. I am indebted to the following for particularly full discussion or for penetrating questions (which they may well not remember) that made me understand my topic better: Mark Crimmins, Richard Feldman, Matt Fulkerson, Jennifer Nagel, Calvin Normore, Howard Nye, John Perry, Gurpreet Rattan, Susanna Siegel, Barry Smith, and Jonathan Weisberg. An anonymous referee's comments were invaluable in ridding the paper of residual confusion. 
Moore's. Sensory exploration can free us of certain sorts of doubt, I argue, but it cannot neutralize sceptical doubt. I will attempt to define and differentiate sceptical and empirical doubt, and thus to delimit the scope of the certainty that sensory exploration is capable of delivering.

Cumulatively, the argument of the paper lends support to a central tenet of traditional empiricism, namely that the senses give us autonomous knowledge of a special domain of properties. Thus, my position opposes those who hold that the knowledge given to us by the senses invariably requires background theoretical (i.e., non-sensory) knowledge.

\section{Sensory Exploration: The Story of Liz}

Someone asks Liz what colour the object in her hand is. It looks orange to her; she experiences it as orange. She concludes that it is orange.

Liz is implicitly using:

Appearance Reasoning That something sensorily appears a certain way-that it is experienced in this way-is prima facie reason to believe that it is this way.

I take Appearance Reasoning to be primitive: the reason-giving power of sensory appearance cannot be justified in terms of anything else. I take it to be a foundational principle of epistemology. However, appearances are not conclusive. The orange look of the object might be a trick of the light-the object might actually be brown or red. Thus, though its appearance gives Liz reason to believe that the object in her hand is orange, she may discount her visual experience because of other information. Sensory experience is, most epistemologists agree, defeasible in this way. It is a prima facie reason: additional information can render it worthless with regard to the conclusions previously drawn from it. ${ }^{1}$

${ }_{1}$ My position on the fundamentality of Consilience Reasoning (see section II below) is inspired by the position on Appearance Reasoning taken by John Pollock (1974), Tyler Burge (2003), and especially James Pryor (2000). Many philosophers, including notably Lawrence BonJour (1985), 
In light of her glance and by Appearance Reasoning, Liz is inclined to think that the object in her hand is orange, but now somebody challenges her: "Do you want to bet $\$ 20$ on it?" The stakes are higher now: she wants to be sure. And this is what she does. She closes her eyes for a few moments to rest them; she puts on her glasses or screws up her eyes to improve focus; she takes the object into good bright light; she brings it closer to her eyes to optimize focus and detail; she removes or covers up any deeply coloured frame that might distort the colour; she checks specular reflections (i.e., the shine and highlights visible on the surfaces of objects in the scene) for clues about the colour of the illumination; she turns the object over in her hand to check on how it looks when light strikes it from different angles and to confirm that the little markings she sees on the surface are indentations (as she originally thought) not smudges.

Liz's actions form a perceptual procedure ${ }^{2}$ that is partly innate, partly learned. This procedure is an example of what I call sensory exploration. Eleanor Gibson (1988) has described something like this, in the following terms:

Action participates in perception ... Information about things and events exists in ambient arrays of energy. Actions have consequences that turn up new information about the environment. (Ibid 6)

Gibson notes that this kind of active perception is, in a sense, learned, ${ }^{3}$ and that it involves skill and discrimination. As infants, each of us discovered that certain ways

oppose this view, but it is not my quarry in this paper, and I will not attempt to argue in support of it. I think of my project as providing evidence against BonJour's coherentism, but some parts of it could perhaps be recast within such a framework.

${ }^{2}$ Sensory exploration is a perceptual procedure in the sense that it involves a good deal more than passive sensation, does not depend on background belief, and is something that the subject undertakes in order to arrive at perceptual belief.

${ }^{3}$ Psychologists sometimes assimilate developmental (i.e., ontogenetic) processes to learning: they speak of language "learning" in infants, for example. There are processes that simply develop in an infant given sufficiently varied stimulation. As "poverty of the stimulus" arguments show (see Segal 2007 for a survey), these are innate, as are least some of the processes that interest Gibson. Call 
of examining things yield "new information about the environment." The first phase of this discovery takes place in the first four months of life, Gibson says:

Visual attention to objects is minimal, but discovery of some basic properties of objects is made possible by visual attention to motion and by the active haptic system of mouthing. Sounds accompanying events are attended to. (ibid 8)

In the second phase, the development of the "manual exploratory system" enables attention to objects: infants grasp things and thus discover objecthood. Finally, starting at about eight months, "spontaneous, self-initiated locomotion makes possible discovery of properties of the extended environment around corners, behind obstacles, and behind oneself."

In the first year of life, then, infants spontaneously develop a repertoire of exploratory actions. By manipulating things, they develop a sense of how things look, sound, and feel from different points of view, and (developmentally) learn how to arrive at stable perceptions ${ }^{4}$ that reconcile and synthesize these variations of appearance. (I would speculate that these actions stem from "core" knowledgegathering abilities, where 'core' is to be understood in the sense of Elizabeth Spelke 2000: "they build on component cognitive systems with a long ontogenetic and phylogenetic history.") Later, these abilities are supplemented by absorption from the culture: sensitivities to music, visual art, tastes, and smells will be developed with the aid of more experienced members of the community. Every adult has a repertoire of such procedures, and many continue to acquire new ones well into old age. Not every adult is equally skilled at every type of perception, but there are some areas in which just about every adult is adequately skilled. Gibson describes how

these processes of "developmental learning." Some of the processes that interest me are experientially or culturally, not developmentally, learned.

4 My use of the term 'perception' is unusual, since philosophers often take perception to be the momentary appearance of an external object. However, Gibson evidently takes perception to be an extended process, and I follow her in this. I will be arguing that the end result of this process is, when all goes well, a stable informational state. I am mostly concerned in this paper with the beliefs that humans draw from such perceptions, and so the unusual use of the term will not much intrude. 
such exploratory activity increases the range of object-properties available to a perceiver. In my view, such exploration is a neglected, but essential, part of how animals and humans perceive things. In this paper, I am concerned with the epistemological status of beliefs arrived at by sensory exploration.

Back to Liz. She knows that her colour vision is adequate to the simple task that faces her. (Possibly some fine test will reveal deficiencies and limitations; perhaps, she would have trouble perceptually parsing an Ishihara plate in which orange dots form a ' 5 ' against a background of red and green dots. However this may be, she knows that she can tell whether a large, chromatically undifferentiated object is orange.) Let's suppose that she is a skilled perceiver of colour-over the course of her life she has come to know most of the probing actions one should perform when attempting to determine colour in tricky situations. (Most colour perceivers are skilled enough to succeed at the simple task that Liz undertakes, but let's suppose that Liz is better than average-more careful, more sensitive.) My claim is that when she has gone through her procedure, as described above, she is entitled to be sure. (I will use the term 'sure' as a placeholder until I can introduce the more precise idea of empirical certainty.) Being a gambling woman, she is now willing to bet $\$ 20$ (or even $\$ 200$ ) on it.

After all, what room is there for error? She knows that the colour is not a trick of the illumination, since she has examined it in good bright light. And this is so even if she has no access to white (or isochromatic) light. It is good enough if she examines it under more than one polychromatic source of illumination-under open sky (which is bluish) and indoors under (slightly reddish) incandescent light. She makes sure that the orange colour of the object is not a trick of the background: she moves it away from the deeply coloured background on which it initially rested. She also makes sure that her own visual apparatus is in good order: she rests her eyes and optimizes focus. Circumstances may sometimes prevent her from performing all of the exploratory actions she feels she needs to undertake, but in this case, she is unimpeded. She has done what she needs to do to arrive at a stable 
opinion-it's orange, and all of the looks that it presents confirm and support this. Moreover, her perceptual state reflects all of this.

Liz has engaged in a form of sensory exploration: a procedure by which subjects manipulate objects that they are examining, or move their own bodies relative to these targets of examination, in order to get a view of them that (a) systematically eliminates grounds for doubt about the correctness of previously arrived at opinion, and (b) affords additional sensory evidence in support of a perceptual belief that was previously underdetermined. Notice that as I understand it, sensory exploration demands active examination, not just the sensory experiences generated thereby. (Later, I'll say why active examination is required.)

Of course, there are people who are gullible and discount their own careful examination of an object. They may compulsively worry that they have not been careful enough (in the way that people worry about not having turned off their stoves). But this would be misplaced, as Liz realizes. Or they may have come to believe that Benjamin Moore now makes a red paint that misleadingly looks orange in all viewing conditions. But Liz knows that this is nonsense: there is no such thing as a red object that always looks orange. There are people who have all the evidence they need to claim a particular level of epistemic confidence, but fail nevertheless to make the psychological step to such confidence. So we should distinguish between (a) possessing adequate grounds for the elimination of doubt, (b) believing something on such grounds, and thus having a belief on grounds that cannot err or be defeated, and (c) actually feeling certain on these grounds. In this paper, I am primarily interested in (a), in showing that sensory exploration eliminates grounds for doubt. I assume that in the normal course of events, (b) and (c) come to pass. Let's stipulate that in the case of Liz, it does. In this respect, she is not only a competent perceiver, but also a competent knower; she follows good epistemic practices. There are some who fail in this regard, but this does not detract from the sufficiency of the evidence that she, and they, possess at stage (a).

Intuition 1: Liz has conclusive reason to believe that the object in her hand is orange. Bracketing scepticism (and one other kind of doubt that 
I'll discuss later), full sensory exploration eliminates any reason she might have had to doubt this. Consequently, she is entitled to be sure that it is orange. And she is sure of this.

Intuition 1 is true of sensory properties, I claim (though not of all sensory properties ${ }^{5}$ ). This includes complex sensory properties such as the look of a maple tree and the sound of a minor scale. ${ }^{6}$ (I shall say a bit more about complex appearances in section VII.) However, I shall argue, it is not true of non-sensory properties, such as natural kinds and material composition. Liz cannot, as I shall later argue, be sure that the object in her hand is an orange.

A few important things should be noted at the outset.

First, Liz is using only her perceptual capacities in assuring herself of the colour of the object in her hands. (I am stipulating, without further argument, that certain simple actions are part of the perceptual process.) She is not using theoretical knowledge about reflectance or illumination, or about the reliability of her own senses, or background knowledge about the things that she perceives. (More about this in section II.) Her perceptual knowledge is, in this sense, autonomous. ${ }^{7}$

${ }^{5}$ In section III, I discuss limitations on the range of properties available to exploration.

${ }^{6}$ I assume that there is a look $L M$ that maple trees have, and that this can be visually discerned. Discerning $L M$ requires active interaction with the tree: you may need to look at its many parts in succession; you may need to walk around it, or get on a ladder to examine its leaves. Of course, it takes extra-perceptual knowledge to identify $L M$ as the look of maple trees.

7 I thus disagree with those who hold that perceptual knowledge rests on background beliefs. Husserl and Wittgenstein were among these-see Dagfinn Føllesdal's (2005) discussion. Husserl believes that belief is ultimately justified by what he calls a "life-world", a cumulative store of culturally dependent, but pretheoretic, knowledge. And Wittgenstein similarly holds that evidence is grounded in a network of pre-existing belief. He seems to hold that certainty pertains to these background beliefs: it lies apart "from the route travelled by enquiry" $(1977,88)$. This statement should, however, be treated with caution, since Wittgenstein's conception of certainty is contextdependent and not, in any straightforward way, an assessment of evidential strength. 
But second, she is using her senses actively. She does not rely simply on experiences that happen to come her way, but purposefully interrogates the object of examination for critical experience in circumstances she controls. ${ }^{8}$ As stated above, she manipulates the object under examination in order to gain evidence relevant to her beliefs, and (though this might not always be possible) she satisfies herself in this case that she has eliminated all sources of doubt (aside from sceptical doubt).

Notwithstanding her agency, which may require a certain amount of skill and reflection, Liz's behaviour is demotic: nothing she does requires specialized know-how or instruments. Some instances of sensory exploration require skill: wine-tasting is an obvious example; colour perception can demand skill in professional contexts (decorating, painting). However, these skills and methods are independently discovered by all cultures in the right material circumstances; they cannot be kept secret by specialized guilds; they require no special instruments. Sensory exploration is low-tech. ${ }^{9}$

Finally, what she comes to know through this process is object colour, not just the quality of her own experience. Some empiricists insist that we can know the quality of our own experiences with certainty, and

${ }^{8}$ Self-awareness of action is inherently multimodal, inasmuch as it involves kinesthesis, touch, and "agentive experiences" (Bayne 2011).

${ }^{9}$ What about Liz's glasses? Do they count as a specialized instrument? For my purposes, it is not necessary to resolve this question: I could simply stipulate that full sensory exploration is not available to short sighted people. However, it strikes me as important that one does not have to learn how to see with glasses. They simply restore sight, and allow one to look and see in the manner that humans instinctively do. This is not true, for example, of microscopes, which require interaction with a fixed eyepiece. Moreover, glasses preserve the usual connections with the other senses: with them I reach for things in just the same way as somebody with uncorrected vision does. This too is not true of microscopes. Thus, one could say, glasses are high-tech means of restoring vision so that people can engage in low-tech activities of seeing and looking. 
some attempt to make this the foundation of all empirical knowledge. The problem they face is how to move from knowledge about experience to knowledge about external things and the qualities that these external things possess independently of any perceiver. Some epistemologists have tried to underwrite this move by noting that sensory experiences give us defeasible reasons to believe that external objects are a certain way: reasons that can be defeated by knowledge of interfering or abnormal circumstances. My point is that (bracketing scepticism etc.) active exploration provides us, in the limit, with indefeasible reason for belief in mind-independent facts. Liz's belief about the colour of the object in her hand has already been tested for errors and distortions, and is proof against them.

\section{How Does Sensory Exploration Work?}

Active sensory exploration is ubiquitous in everyday life.

How far away is something? You look, but you also pace it off. (Note the involvement of more than one sense in this case.)

What is its shape? You look at it from different angles by turning it over in your hands or walking around it. ${ }^{10}$ If the object is small, we also explore it by touch.

What is your guest talking about? You turn the TV down, cup your ears, and look at her mouth.

What is smelling up your refrigerator? You pick each item up, bring it to your nose, and sniff.

10 This is how we typically test the difference between two-dimensional barn-facades, such as those envisaged by Alvin Goldman (1976), and real three-dimensional barns-in-the-round. Exploration does not depend on an external condition, reliability, as experience does, according to Goldman. Its authority arises from the skilful elimination of defeaters. 
How does this wine taste? You smell it after swirling it around in your glass, and then you swish it around in your mouth for a sufficient length of time. Finally you spit or swallow, and savour the "finish".

How do these processes work? There are two sorts of question here. First, what information does sensory exploration provide? Why is it reliable? These questions demand scientific investigation. Psychological, neurological, and physical theories tell us about the external correlates of perception, and about how our sensory systems process data. They tell us how sensory exploration proceeds, and why it is reliable.

A second type of question is this: What is the epistemic value of sensory exploration? How does the exploratory procedure that Liz undertakes warrant her surety regarding her conclusion? What is the analogue of Appearance Reasoning in this domain? The answer to this second question does not rest on scientific theories. Liz does not believe that the object in her hand is orange on the grounds that scientific investigation has revealed her techniques to be reliable. Her employment of exploratory techniques is intuitive and natural-many of these techniques are developmentally learned (see note 3); people in ancient times used the same techniques; people in all cultures now do the same. Cats and dogs and non-human primates use analogous methods-they circle, manipulate, probe, sniff, and tongue objects they wish to investigate. This shows that they, and by extension we humans, put our trust in sensory exploration for very simple primitive reasons. It could be that most, or even all, people believe that sensory exploration is reliable. The fact remains that they are using techniques and procedures that are a natural extension of animal techniques, and which are not shaped or modified by beliefs about reliability. (Compare Appearance Reasoning: Liz does not believe that experience gives her prima facie grounds for belief because science tells her that it is often, but not always, reliable. Appearance Reasoning is primitive.)

Though the epistemic question does not rest on background beliefs, the scientific question is relevant and important, for it can guide us through a thicket of intuitions-attention to the science will save us from errors of asserting that 
something is certain when actually it cannot be (and is not taken to be in the culture). Though it is the epistemological (i.e., the second) question that I really want to address here-the question of justification, not the question of why exploration produces reliable belief-caution dictates that I should let myself be guided by the empirical facts. I do not want to end up inadvertently incorporating into perceptual justification any procedure that empirical investigation has revealed to be unreliable. If I fall into such error, the science will prove me wrong.

In this spirit, let me briefly address the scientific question. Broadly speaking, there are three types of error in perceptual judgement based on experience. First, the conditions of observation may be misleading: for example, you may look at something at an odd angle and thus misjudge its shape; you may listen to a sound in a echo-filled space, and thus misjudge its location; you may misjudge the taste of something because some other strong taste interferes. Second, the observer's own condition may not be optimal: you can be dazzled, deafened, or have your temperature sensitivity distorted by immersing your hand in ice water. Lastly, the observer's experience may be insufficient to the judgement: you may glance at something and receive misleading information about its colour or shape; you may gulp some cold white wine on a hot day, and in your haste fail to register its true flavour.

Sensory exploration is a purposeful, technologically unassisted way of checking up on and correcting these sorts of error (and of gaining additional evidence when the subject is unsure of the object's sensory properties). By observing things under a sufficient variety of conditions, you arrive at perception that is increasingly less prone to error due to tricky conditions of observation. It is important to note that in order to eliminate error of this sort, it is not necessary to view things in all possible situations-a procedure that would be impossible to complete. Viewing something under several different polychromatic sources of 
illumination is sufficient to resolve metamerism ${ }^{11}$ and eliminate misperception of colour. ${ }^{12}$ If you view an object from three different angles, each of which reveals three sides of the object, and together revealing all its sides, you have the information needed to eliminate hidden irregularities of shape-this ability is enhanced if the lighting is somewhat oblique, and creates shadows and shading. If one circles around a kitchen sniffing, one can detect the source of various different smells. And so on. Similarly, sensory exploration includes optimizing the perceiver's own condition. Eyes must be rested, background noise suppressed, hands must be warm and dry, but not hot, etc. Finally, we must appeal to a sufficiency of information sources. To taste wine and food, it is not enough to gulp it: one has to make sure the entire flavour system comes into play: orthonasal and retronasal olfaction, taste in all parts of the mouth, and the trigeminal system that detects the heat of pepper and coolness of mint.

These facts, rooted in scientific theory, explain why different perspectives cumulatively enough about the interactions of observer, observed object, and environment to arrive at stable perception. But the judgements we derive from such perception are not based on the facts just mentioned. Rather, they are based on a basic epistemological principle. The following illustrates the principle. Suppose one wants to know the shape of some small and portable object, such as a diamond. It looks like a regular octahedron, but feeling it with one's fingers, one finds some irregularities and ridges. So one builds up a more complex shape profile by examining it from lots of different angles, feeling it with one's fingers, and

11 There are pairs of distinct reflectance profiles that look the same in certain illumination conditions. This is the phenomenon of metamerism. Reflectance profiles that are indistinguishable in one sort of illumination will look different under different illumination.

12 In fact, as Oliver Sacks (1998) and Justin Broackes (2010) recount, viewing things under different conditions of illumination is a good way for even colour blind people to discern (and even see) colour. Broackes shows how red things will darken more when rotated away from the reddish light of the evening sun (and darken less from noon) thus differentiating them from, for example, blue things (which are relatively dark in reddish light, and thus darken less upon rotation). 
correlating visual and tactual information gained as one does so. The process gives one more and more information as it proceeds. There is, however, a limit to discovery. After a time, it is apparent that one is merely seeing and feeling more of what one has seen and felt before. At this point, one can learn no more-at least, not about the relatively coarse-grained properties of the object.

Similarly, colour. Entering the room at the Art Institute of Chicago, one catches sight of Seurat's magnificent Sunday Afternoon and marvels at the luminescent quality of the flat coloured patches of grass. Going up close, one sees that in fact these patches consist of small dots of paint of many different colours. Alternately approaching and retreating one apprehends both the pointillism (up close) and the flatness of the colour (from far away). One learns how the one view fades into the other. After a time, approaching it from new angles and viewing it from different distances ceases to add information, and opinion becomes more and more stable. There is a point at which one can learn nothing more about its colour. This is not to say that one will ever learn everything there is to learn. One will never know every single fleck. Rather: there is a succession of stages at which one's beliefs about the sensory properties of the painting stabilize at progressively finer levels of detail-one may have a stable opinion about a fairly crude property of the painting (such as how many people it portrays) while still oscillating about fine detail.

It has been claimed that the differing appearances of things from different perspectives are either irreconcilable or reconcilable only with the help of theory. C. L. Hardin (1988), for example, argues that the supposedly conflicting viewpointdependent appearances of the Seurat indicate that it is not any colour intrinsically, the appearances being simply inconsistent with one another. It is pointillist-up-close and flat-from-afar, and that is all that can be said, so Hardin suggests. ${ }^{13}$ It could also be argued (i.e., taking a different direction than Hardin) that "conflicting"

13 Hardin calls this position "chromatic democracy": see Jonathan Cohen 2009, p. 24 for another take on essentially the same approach. 
experiences can only be theoretically reconciled. Sophisticated knowledge is required to show us how the dots meld and produce a complex colour from afar.

These responses seem counter-intuitive to me. When one moves toward and away from the Seurat, one develops a perceptual representation of the colours in the painting: the artist has painted dots of many colours so that from a distance they look flat and luminous. ${ }^{14}$ There is no real conflict among these appearances: they are consistent with one another, though it may not immediately be evident how to reconcile them. By exploration, however, we gradually accumulate grounds sufficient for the settled opinion that the painting is actually pointillist, though it looks flat from a distance. Theory might help one understand how the artist accomplished this; exploration, however, is quite sufficient to assure one that this is how it is. This seems even clearer in the case of shape. There are bumps and imperfections on a glassy surface that vision cannot detect; haptic exploration, however, reveals it as not perfectly smooth. Shapes maybe regular viewed from one side; but irregularities are easily detected upon rotation, ideally in oblique lighting. Thus, touch and purposive action compensate for and supplement the inadequacies of passive vision. A smell may be indistinct in the living room, but a trip to the kitchen not only reveals what it is, but also where it is. Sensory information gained at different moments is not, as it were, filed separately and reconciled by an overarching theory. Rather it is used to construct a coherent model of things, their properties, and their locations. And this is done by everyday methods of sensory exploration that can be enhanced by coaching, but which are universally available (at least to all those who are not sensorily deprived).

${ }^{14}$ I can imagine certain philosophers saying that it is equally true that the artist painted the scene in flat colours in such a way that it looks pointillist from up close. I take this to be more witty than insightful. I should also remark, in response to Locke's conundrum, "Blood to the naked eye appears all red; but by a good Microscope, wherein its lesser parts appear, shews only some few Globules of Red, swimming in pellucid Liquor," (Essay II, XXIII, 11) that I take blood to be red, because sensory exploration is low-tech, and views through a microscope are not (see note 9). 
Sensory exploration is an active process of interrogating an object and gathering its different appearances in a controlled way. Initially, deeper exploration can create confusion. An object looks orange when viewed straight on, but yellow when its green surround is removed. Which is it? At first, the answer might not be clear. After a time, however, given sufficient access and the opportunity to observe the object in a sufficient variety of conditions, a normal perceiver arrives at a settled opinion. Some time after this, after even more exploration, it becomes clear that additional information adds no additional warrant relative to a particular judgement. At some juncture, I realize that I know all there is to know about the colour of a particular area of the Seurat. I may not be sure how the painting looks from a hitherto untested perspective; I may explore it anew to refresh my memory: however, further examination adds nothing to the strength of my reasons for my judgement concerning the colour of a particular region of the painting. I'll call this limit condition consilience.

In light of the foregoing observations, I propose the following as a fundamental and primitive principle of perceptual knowledge, analogous to the principle of Appearance Reasoning stated earlier:

\section{Consilience Reasoning}

a. Sensory exploration leads to consilient opinion about $x$ : that is, opinion that cannot be supplemented or contradicted by further perceptual interaction with $x$,

b. Subjects are capable of knowing that they have arrived at consilient opinion, and

c. When a subject knowingly arrives at consilient opinion, s/he has indefeasible entitlement to believe this opinion (bracketing two kinds of non-empirical doubt that will be discussed later).

I want to allow that subjects may sometimes think that they have arrived at consilient opinion, when in fact they have under-explored their target objects-it is possible to be hasty or careless. In these circumstances, they think they have 
grounds for surety, but they do not in fact have such grounds. My point is not so much about self-awareness. It is that consilience reasoning offers us conclusive and indefeasible grounds for belief in sufficiently simple cases: the case of Liz and object colour is one such simple case; the determination of how many faces a diamond has is another. For this reason, when a subject carefully and skilfully arrives at an consilient perceptual belief under sensory exploration, she is entitled to be certain. If, further, she feels certain of her belief under such circumstances, she is justified in feeling that way.

There may, of course, be borderline cases: How sure can one be that a melody that one is listening to has been transposed into a minor key? How sure that the building one is looking at is taller than it is wide? That two colour patches are exactly the same? Here social endorsement of skill and public verification plays a role in certification of consilience. These are complex matters, and I'll put them to one side-I acknowledge later that though exploration enables us to be sure that something is, say, orange, it does not generally allow us to be sure what precise shade of orange it is. All I need for my present purposes is that there is a substantial body of fact that one is able to conclusively verify (bracketing scepticism).

One last comment about exploration. Though I contrast exploration with experience, exploration does, of course, consist, in part, of experiences of the object being examined-experiences produced by a subject's active examination of the object under critical perspectives. When I turn something over in my hands to explore its shape and colour, I knowingly put myself in the way of a series of experiences, which I then use to arrive at consilient opinion. ${ }^{15}$

The question may be asked: is it merely the series of experiences of the object that gives me knowledge of its shape and colour, or does my awareness of active and purposeful exploration also play a role. Epistemologists who wish to assert the primacy of sensory experience may insist on the former view: that is, they

${ }^{15}$ A robot might, however, perceptually examine an object in the same way a human does, though without sensory experience-and arrive at a fully explored conclusion by consilience. 
may want to hold that the evidential content that enables me to arrive at a wellfounded opinion about the object lies entirely in the experiences I have of the object, not in my awareness of the actions that produce these experiences. They acknowledge, of course, that my exploratory actions play a role in producing these experiences. Nevertheless, they would insist, my awareness of these actions does not afford me evidence regarding the shape and colour of the object I am examining.

Though I cannot argue the point at length here, my view is that purposeful exploratory activity and the accompanying sense of agency provides the subject with essential evidence. Suppose a perceiver has some reason to doubt that he has full information about the shape of some large object, and wants to look at it from another angle. Unfortunately for him, he is immobilized and deprived of kinaesthetic sensation and bodily sensation. However, he is wheeled around, and offered what seem to be multiple views of the object from different perspectives-the very same perspectives as those he had wished to obtain. In this immobilized and passive condition, he has no direct knowledge of what these perspectives are-he does not, for example, know whether the face of the object that is now revealed is the one that was to the top, relative to his earlier view, or to the right. Since he has no sense of his own position or movement, it is for him as if he had been presented with views of an object seen from different angles, but given no information about how his position changed with regard to the object. In a view such as the one he has, he cannot even differentiate views from above and from below. (Of course, somebody might tell him how his position is being manipulated, but this provides only indirect evidence, which relies for its credibility on extra-sensory premises.) So the first point for the self-awareness of exploratory action is this: it provides indexed awareness and continuity of perspective.

Moreover, in the passively presented sequence, the immobilized patient is fed experiences in an order not determined by himself. He cannot test critical appearances, or go back to check. In active exploration, the subject is checking up on specific sources of error. He wonders if his angle of view distorts the apparent shape of the thing he is examining, and changes his perspective to eliminate this worry. He 
knows how his series of experiences relates to critical perspectives on the object he seeks. He knows how he expects the object to appear, how his expectations were met, and how they were revised. The orderly march to consilience depends on the object's responsiveness to interrogation. This is the second point: in active exploration, evidence is presented in response to specific queries, and has relevance relative to these questions. This is part of what allows a subject to know that he has arrived at consilient opinion.

A final and crucial point is this. As we learned from Eleanor Gibson, the externalization of the perceptual object comes about through active exploration. Why is your visual experience an experience of something outside you, not simply of random events in your eyes or brain? Similarly, touch? One major reason is that when you purposefully explore external objects, they feel distinct from you and your body. Their orderly and predictable changes of appearance consonant with your felt changes in position assure you that they are external to you. Thus, a mere series of experiences (as opposed to a series of experiences known to be produced by volitional action) does not even give you awareness of things as external, much less knowledge or certainty of them as such. (More about this in the next section.)

In sum, then, I am proposing that Consilience Reasoning is a fundamental principle of epistemic reasoning, and proposing moreover that self-conscious exploration is part of this principle. Perceivers know by instinct and by cultural learning that certain procedures lead to stable opinion when conscientiously and purposefully carried out. The conclusions that are arrived at by Consilience Reasoning may not be exhaustive: at the limit of sensory exploration, certain conclusions may be exhaustively validated, while others remain open to revision, and hence probable but uncertain. There are scientifically validated reasons why these procedures lead to these results, but these reasons are not what validate the perceiver's knowledge. A perceiver's knowledge is validated, instead, by Consilience Reasoning. 


\section{The Domain of Sensory Exploration}

From what I have said so far, the reader might get the impression that sensory exploration is simply a superior alternative to simple sensory experience-the alternative that any responsible knower would prefer. And this is true to some extent. You can't just glance at something to know its shape and colour: you have to examine it carefully. You can't just quaff a glass of wine to know how it tastes: you have to give it time in your mouth (and nose). However, there are important differences between exploration and experience that make them not strictly comparable in many areas. For there are certain matters that can only be known by exploration, others of which experience affords evidence of at least equal probity, and still others that can only be known by experience only, not exploration.

One important class of things known only by exploration is those of which experience can only offer subjective knowledge. Consider pain. Philosophers rightly emphasize that pain sensation is sufficient for being in pain. If you wrench your wrist while hoisting a heavy bag into the trunk of your car, the sudden shooting sensation cannot lie. It implies that you are in pain; indeed, the sensation is your pain. The information that this sensation offers you is that it has occurred, and that you are thus in pain.

But now suppose that you consult your doctor over the telephone to determine whether medical intervention is needed. The doctor wants to know a lot about the pain (or more accurately, about the condition of your wrist). ${ }^{16}$ To answer her questions, you will need to palpate your wrist to determine whether the pain is superficial or deep, exert pressure to find out where exactly it is tender, probe to find lumps or swellings where the pain is localized, and carefully describe the intensity and nature of the pain. These exploratory activities bring out a good deal

16 The word 'pain' is sometimes used to characterize a sensation, sometimes to characterize the bodily cause of this sensation. It is, in this way, like words for secondary qualities. There is a difference, though, because colour words etc. denote external qualities primarily, and qualities of sensations only secondarily, whereas with 'pain' it is the other way around. 
about the nature of the pain, or, if you prefer, of what is causing it. I interact with my wrist in order to elicit experiences under specific critical conditions, and in this way I come to know about something that is mind-independent. Full examination and consilience may or may not be achievable in this series of interactions; my present point is simply that exploration yields knowledge of something that exists independently of the sensations I endure during the process. It informs me about the state of my body in a manner that pain-experience by itself cannot. ${ }^{17}$

This is particularly true of what is known as haptic touch, which includes awareness of cutaneous stimulations in the context of associated bodily movements and actions. ${ }^{18}$ Suppose that you are rummaging around in a drawer, and you bump against a sharp knife. The resulting sensation is devoid of kinaesthetic context. All that you know is that something unpleasant has occurred at a certain location in your body. But now imagine moving your finger carefully along the edge of a knife to test whether it is sharp. At this point your sensory awareness becomes externalized. You feel the knife-edge, not just your finger. This kind of externalization is not exactly the same as in the pain case, where exploration shifts the focus from an event in consciousness to the focus of trauma within your body. With haptic touch the focus shifts from a state of affairs involving your body to something outside it.

17 One complication as regards exploration of pain is that it can create new pain or even trauma. This is the case with Ekbom Syndrome (Hinkle 2011) in which patients, worrying that there are bugs under their skin create lesions by trying to remove the bugs. These lesions then reinforce their delusional conviction that they have bugs under the skin. Sensory exploration must be skilled in order to have probative force, and in the case of pain, it is not easy to acquire the requisite skill level. I am grateful to Matt Fulkerson for this reference.

18 Haptic touch is interestingly discussed by J. J. Gibson (1962, 1966). Gibson recounts a tradition of treating it as pressure plus kinesthesis, and persuasively attributes this analysis to "the problems and frustrations of those who tried to classify the body senses and pin them down to corresponding receptors and stimuli" $(1966,98)$. Note that I treat it as including awareness of action, i.e., of agency. 
But the point that I want to make is similar. The target of exploration is not exactly the same states of affairs that are revealed by bare experience. ${ }^{19}$

Something similar is true of vision. Susanna Siegel (2006) describes a case of a small doll seen by a subject sitting on a shelf. When the subject moves toward the doll, it subtends a larger visual angle; when she changes her angle of view, hitherto unrevealed sides are revealed, and so on. Generally speaking, the subject's view of the doll is responsive to changes of the subject's perspective on the doll. Siegel tries to imagine what would happen if the view of the doll ceased to respond in this way. The subject turns around, but the doll stays where it is in her visual field; she tries to crane her neck to see its back, but regardless of her position, it continues to present the same view. She closes her eyes or covers them up, and still she continues to see the doll.

At some point, Siegel says, the doll's unresponsiveness to changes of perspective will make it seem as if it is not an external object at all. Just as with touch, then, externalization is tied up with visual exploration. A momentary, passive visual experience does not differentiate between objects that respond to changes in perspective and those that do not. The point that I want to take from Siegel's example is that perceptual presentations of objects as existing independently of the perceiver-what Husserl (1913) called the "natural attitude" in perceptiondepend on the activity of the perceiver. (J. J. Gibson 1962 makes a similar point about active touch. ${ }^{20}$ )

A second point to note is that, by contrast with experience, sensory exploration is not usually restricted to a single quality. Normally, exploration aims at building up a sensory profile of an environmental zone. Think of your office, or

19 Here, I am very much indebted to Matthew Fulkerson (2010), whose work on touch inspired me to formulate the notion of sensory exploration.

20 Tyler Burge (2010) discusses the role of perceptual constancies in our conception of things as existing independently of ourselves. Sensory exploration is another such "origin of objectivity." 
your kitchen. There is a way that it feels when you enter; a characteristic way it reveals itself when you switch on the lights; a familiar suite of smells (of books, furniture, spices, etc.); a way it is traversed, and so on. Unlike experience, exploration encodes these things allocentrically: objects are spatially represented as they are to one another, not as they appear from a particular point of view. (Thus, left and behind and other such perspectival relations are erased in the profiles arrived at by exploration.) As I said earlier, sensory exploration is used to construct a coherent model of things, their properties, and their locations, a model of zone. The environmental zone and profile are not the focus of this paper: I am concerned here with how exploration furnishes us with conclusive reasons for beliefs. Nevertheless, it is worth keeping in mind, for it is this wider scope of sensory exploration that accounts for its involvement with complex sensory properties: the feel and look of velvet; the look, smell, temperature, mouth-feel, taste, and aftertaste of a cup of coffee, the sounds and sights of a live opera performance, and so on.

Here, briefly, are some further contrasts between the evidential value of sensory experience and of sensory exploration.

1. Being temporally extended, exploration is primarily concerned with enduring properties of things, while experience can give us knowledge of fleeting occurrences. For example, it is not possible to explore whether a tennis ball has fallen in or out, or what words somebody shouted out, or whose fault an accidental collision with another pedestrian was.

2. Experience is self-revealing: it is never in question what quality I am experiencing. I cannot be in doubt whether something looks blue or looks red. However, exploration requires skill and discernment. This is particularly true of complex appearances. Does that fabric look like velvet or like silk? Does this wine have a taste of blackberries or of black currants? Such complex appearances are not only temporally extended, but variable with regard to temporal sequence. The look of velvet, for example, includes a diffuse sheen when the incident light is oblique: when I ascertain whether something has the 
look of velvet, it makes no difference whether I check for this sheen early or late in my exploratory process.

3. Experience of external things is immediate, and does not require reflexive knowledge. However, exploration is self-aware: the subject has to know what he is doing.

4. Experience is determinate: I cannot experience something as blue without experiencing it as a determinate shade of blue. Exploration, by contrast, may not yield such determinate answers. Liz (section I above) may arrive by exploration at a consilient opinion that the object in her hand is orange, but she may never become sure what specific shade of orange it is. Similarly, I can be sure by exploration that the object in my hand is roughly an octahedron-but I cannot be sure that its faces are perfect planes.

One last point, briefly. Suppose I worry that I might be colour-blind. Would this be reason to doubt that two things that look the same colour (after exploration) are actually the same colour? Yes and no. No: though colour blind people have only a coarse grained capacity to differentiate colours, they can be just as sure about their colours-colours defined by their discriminatory abilities-as better colourdifferentiators can be about theirs. Once I have explored the two things thoroughly, I can be sure that they are the same colour-relative to my colours. But, also, yes. For I can doubt that the things in question are "actually the same colour"-i.e., relative to the colours others experience. This, however, is a theoretical worry that is not based on my experience. (I'll mention this difficulty again in section VII.)

\section{Scepticism}

There is a great deal more that can and should be said about sensory exploration. It is particularly pressing to know about (a) the different exploratory procedures that are used to learn about different sensory properties (colour, auditory timbre, voice identity, ... ), and (b) the differences between the contact senses (touch and olfaction) and the distal senses (vision and audition)-smell is an interesting inbetween case-with respect to the essential role played by sensory exploration. 
These issues will have to be deferred, however, to another occasion. My immediate concern is with certainty.

Earlier, I said (Intuition 1) that bracketing scepticism a perceiver has no room to doubt a judgement produced by full sensory exploration, i.e., exploration that has led to consilient opinion. Clearly, however, full sensory exploration does not provide us with any kind of surety against sceptical scenarios: I could seem to explore something fully but arrive at false opinions because I am dreaming, or am a brain in a vat, or am undergoing a particularly strong form of trans-cranial stimulation. So to capture the intuition that full sensory exploration yields a kind of certainty, we need to exclude sceptical doubt. But what is sceptical doubt? And how is it different from the kind of doubt that sensory exploration helps dispel?

One way to go about answering these questions is to reflect on the epistemic function of the senses. They serve to inform us of specific place- and time-bound circumstances. My senses tell me of how things are here and now, and sensory exploration attempts to validate their content. So understood, sensory exploration can only remove sources of doubt that relate specifically to my present situation. This is why it does not remove sceptical doubt.

In this vein, suppose that Liz is holding two objects in her hands. One $(O)$ looks orange, the other $(R)$ red. Suppose that putting all other reasons for doubt to one side, she doubts that $O$ is orange because she cannot rule out that she is dreaming. This is, for exactly the same reasons, grounds for doubting also that $R$ is red (as well as every other proposition that she knows by her senses). By contrast, suppose that she doubts that $O$ is orange because she thinks that $O$ 's green surround distorts its colour. This is not a reason for doubting that $R$ is red. Sensory exploration can ameliorate the second kind of doubt-Liz can remove or mask the putatively distorting green surround. But sensory exploration cannot dispel the first doubt. Sceptical doubt is not specific to a particular state of affairs revealed by the senses; empirical doubt is. Thus: 
Intuition 2: Sceptical doubt spreads to unrelated empirical propositions; empirical doubt is confined to conditions that obtain in a particular place and time.

There is clearly some weight behind Intuition 2, but it is all too easy to come up with a counter-example. Suppose that Liz worries that a mad scientist is transcranially interfering with her brain in such a way that $O$ looks orange (though it is actually some other colour). Let's call this a point-sceptical doubt: it is specific to just one (or, at any rate, not all) of the things that Liz senses. The point-sceptical worry does not spread to $R$ because it is irrelevant to $R$. But point-sceptical doubts cannot be removed by sensory exploration. So sensory exploration it would seem that does not remove all non-spreading doubts.

Of course, Liz has no reason to believe anything so farfetched. But sceptical doubts are not based on positive reasons; rather, they are based on interferences that cannot conclusively be ruled out. A sceptical scenario merely has to satisfy the following condition:

Doubt Condition Let $p$ be a proposition that subject $S$ cannot definitively rule false, given $S^{\prime}$ s epistemic position. Then if the truth of $p$ would reduce the strength of $S^{\prime} s$ reasons for believing a proposition $q, p$ is a doubt condition for $q$.

The point-sceptical transcranial interference scenario (TIS) satisfies this condition; it is a reason for doubting that $O$ is orange, but not for doubting that $R$ is red. So it makes problems for Intuition 2.

Still, there is a difference between doubting that $O$ is orange because it has a green surround and doubting that it is orange for the TIS reason. For Liz has no more reason to admit TIS for $O$ than she does to admit it for $R$. By contrast, the distorting-surround worry really does give her stronger reason to worry that $O$ 's colour is distorted than to worry that $R$ 's colour is distorted. Moreover, the distorting surround reason is characteristically sensory: it is a here-and-now worry provided by Liz's sensory condition. 
This reflection leads to a further notion:

Convertibility of Doubt A doubt condition for $p$ is convertible to $q$ for a subject $S$ if there is a similarly structured doubt condition for $q$ that is no less credible given $S^{\prime}$ s epistemic position.

By "structurally similar," I mean something quite simple. Let's suppose, for example, that apparent colour is influenced by both illumination and surround colour. Then a doubt condition based on illumination is structurally similar to one based on surround colour: it impugns one of the determinants of colour appearance. The "no less credible" clause is also quite simple to apply. Suppose that object $O$ has a green surround and so, though it looks orange, Liz doubts that it is orange. Liz looks at $R$ and sees no interfering surround-colour, and nothing else that would distort the colour of $R$. Her doubt that $O$ is orange is not convertible to doubting that $R$ is red, because given her epistemic situation any doubt she harbours concerning $R$ is less credible than her doubt concerning $O$. For instance, she might doubt $R$ for point sceptical reasons, but this is less credible than her sensory doubt condition for $O$.

At this point, I can define our two types of doubt as follows:

Sceptical Doubt $S$ sceptically doubts $p$ if $S^{\prime}$ s doubt condition for $p$ is convertible to all other empirical propositions of the same logical type. ( $p$ and $q$ are of the same logical type if either both are logically simple singular propositions, or both are universally quantified. ${ }^{21}$ )

Empirical Doubt $S$ empirically doubts $p$ if $S$ s doubt condition for $p$ is based on a non-convertible doubt concerning conditions in a particular place and time.

For example:

1. (Not sceptical) You doubt that all ravens are black because you think you have seen a pink raven. This doubt is not convertible to the

21 For present purposes, I exclude negations and unrestricted existentially quantified propositions from consideration, since doubts concerning these are more complex to classify. 
proposition, "All elephants have trunks" because you have not seen a trunkless elephant.

2. (Sceptical) You doubt all ravens are black because you worry that induction does not work. This is a doubt condition for an empirical generalization that is convertible to all other empirical generalizations.

3. (Not sceptical) You doubt that the thing in your hand is pink because you think your high level of inebriation is causing you to hallucinate. This doesn't convert to perceptual beliefs formed when you are sober.

4. (Sceptical) You doubt that the thing in your hand is pink because you cannot rule out transcranial influence. This doubt condition for a singular perceptual belief converts to all other singular perceptual beliefs.

5. (Not sceptical) You worry that you are a brain in a vat, because you see a ribbon announcing your vital signs running at the bottom of your visual field. ${ }^{22}$ Thus, you doubt everything your senses tell you. This is not convertible to doubt regarding the same sensory propositions when no such tape (or other equivalent evidence) is presented.

6. (Sceptical) You worry that you are a brain in a vat based on no empirical evidence. This is convertible to all sensory propositions.

Here, then, is a first step to refining Intuition 1 concerning sensory exploration: sensory exploration removes empirical doubt about the real sensory properties of external things-it removes doubt that does not convert to every other proposition that the senses give a subject reason to believe.

Just to be clear, I am not suggesting that doubt that emanates from nonsensory sources can always be removed. Consider the following scenario (suggested

22 The example is in Jim Pryor (2000). He suggests that it is a sceptical scenario, but one that is prima facie justified. He is presumably demarcating sceptical scenarios by content: any dream, any brain-in-a-vat scenario is sceptical. I am thinking of scepticism structurally. 
by Mark Crimmins). Suppose that somebody tells Liz that she is the subject of an interesting (and unethical) experiment, and that a new form of transcranial interference is being used from a remote location (half way around the world, say) to distort the colour of just $O$. In the light of this testimony, it seems, no amount of exploration will remove all doubt that $O$ is orange. However, she may still be able by sensory exploration to remove non-convertible doubt that $R$ is red. The two propositions are asymmetric with respect to doubt because Liz has positive reason to doubt one but not the other. The $O$-doubt is not convertible to the $R$-doubt. (It would be convertible if Liz lacked positive reason, here in the form of testimony, to think that she may be deceived about $O$.) So here, it seems, we have (contrary to the refined form of Intuition 1) non-convertible doubt that sensory exploration cannot remove.

I want to distinguish this case from one in which Liz simply entertains the possibility that her senses are being interfered as regards one object but not as regards the other. In this case, since she has no reason to differentiate the two objects, her doubt is convertible to doubt about other objects and is therefore a sceptical doubt. This is like case 6 above, the non-empirical brain-in-a-vat doubt. The case that we are presently envisaging is one in which Liz is actually told by someone (perhaps even an expert she trusts) that only her perception of $O$ is being interfered with, not her perception of $R$. Here, her doubt may well be legitimate and non-convertible. It is somewhat like case 5 above, except that it is a point sceptical scenario.

I think we have to allow that scenarios of this sort may vitiate Consilience Reasoning. In a case like this, a subject's epistemic position may be fouled, and thus full exploration may be impossible, not because the procedures are unavailable, but because the subject is in possession of reasons that undercut these procedures, with the result that they do not achieve the normal level of surety. But this does not tell against the possibility of Consilience Reasoning in general, nor against the possibility of being sure, bracketing sceptical doubt. 


\section{Reflexive Doubt}

Now, let us briefly consider a well-known problem that arises out of doubts concerning one's epistemic position. Perform this exercise: mentally calculate the sum of 1087 and 1112. Presumably, you can do this fairly easily-but are you sure of your answer? Normally, just posing this question would make you go back and repeat the calculation. And this would increase your subjective confidence in the answer. Now, some may say: No amount of repetition is enough to maximize your confidence. Even if you have done the sum 29 times, a 30th would raise your justification level, even if only by a very small amount. Thus, you can never possess full surety in the above calculation.

I do not think this is right. After all: you are just doing the same calculation again and again. A repetition does not give you new warrant: it just repeats the old warrant. (Somebody tells you: "Bill and Nora are having an affair." You are a bit deaf and very incredulous, and you respond: "What did you say?" "Bill and Nora are having an affair," your gossipy friend repeats. Do you have better reason to believe the tale?) Repetition may increase your confidence in the answer-but only because it increases your confidence that you have performed the right calculations. It does not increase justification.

Distinguish between doubt about your own epistemic position and doubt about some external object of investigation. Repetition removes or reduces the former, but gives you no additional reason to discount the latter. Repetition is like "checking one's sums": it adds to your confidence in the answer, but not because it gives you additional information. This is why sensory exploration can be full. There is a certain point when you know that you have done what you need to do in order to arrive at consilient opinion. Now it may be that even after this point, you may become more confident about the nature of your epistemic position, because repetition reduces the likelihood of errors in short-term memory and the like. However, your epistemic position cannot itself be improved. At the first threshold point, you know that you have arrived at consilient opinion. 
Here is the final form of Intuition 1:

Definition $X$ is empirically certain of $p$ if $X^{\prime}$ s only reasons for doubting $p$ are either convertible to every other empirical proposition of the same logical type as $p$, or are doubts concerning $X^{\prime}$ s own epistemic position regarding $p$.

Thesis Full sensory exploration leads to empirical certainty.

\section{Certainty}

Now a matter of clarification. I have adopted a fallibilist position about sensory exploration: it can be mistaken if the subject is either in a sceptical scenario or if s/he is wrong about her own epistemic position with regard to how well she has explored her target of investigation. But I am claiming, nevertheless, that the subject is entitled to a form of certainty concerning the explored object. How can a subject be certain of something regarding which it is possible to be wrong?

For my purposes, certainty should be understood in roughly the following way. First, $S$ is entitled to be certain of $p$ only if $p$ is (ontologically) necessary given $S$ 's epistemic position. This implies that $S^{\prime}$ s warrant for believing $p$ cannot be increased or decreased (Reed 2008). Of course, $S$ may believe $p$ for reasons unrelated to her epistemic position. To exclude unmotivated or irrational belief on the part of someone who is in a good position to judge correctly, it is important to add: $S$ is objectively certain of $p$ only if $S$ believes $p$, and for the right reasons.

This outline of certainty is rough and imprecise, but it affords a guide to how to approach this notion. The wrong way is to make certainty a matter of comparison. Sometimes, G. E. Moore seems to go this way. For instance, he says that he cannot prove that he is not dreaming, but that he is nonetheless certain of things that might be false if he were dreaming-for instance, that he is now standing up. Of course, this is precisely the conclusion that I want to endorse, but Moore sometimes seems to arrive at it by comparing the credibility of the alternative:

What if our sceptical philosopher says ... It is logically possible both that you should be having all the sensory experiences you are having ... and yet should be dreaming .. 
. But can any reason be given for saying that it is logically possible? So far as I know nobody ever has, and I don't know anybody ever could. And so long as this is not done, my argument "I know that I am standing up, and therefore I know that I am not dreaming," remains at least as good as his, "You don't know that you are not dreaming, and therefore don't know that you are standing up." (1959) ${ }^{23}$

I demur. Put aside Moore's unmotivated concern that the dream scenario might not be logically possible: of course it is. If your argument for $p$ is only as good as your opponent's argument for $\sim p$, then your warrant for believing that $p$ can be improved.

My approach to empirical certainty is to bracket certain kinds of doubt. Thus, I claim that, given sensory exploration, the only way you can be wrong is if a sceptical scenario turns out to be correct, or if your reflexive beliefs are mistaken. This preserves the logic of certainty as not admitting of augmentation-I do not think that certainty admits of more or less-while at the same time admitting that it is possible to be wrong even when one is objectively certain.

Including and excluding specific kinds of doubt permits us to differentiate between types of certainty. For example:

i. " $1=1$ " is absolutely certain, and subject to no doubts whatsoever (assuming that one can grasp this proposition in a single act).

ii. "I exist" is pragmatically certain, inasmuch as it cannot be doubted for any reason, though the proposition it expresses is not certain.

iii. " $657+431=1088$ " is non-reflexively certain, inasmuch as it is immune to all but reflexive doubt.

iv. "Matter is extended" admits of Cartesian certainty inasmuch as it is immune to all doubt except reflexive doubt and doubt about the content of one's ideas (i.e. about whether one's idea of matter is "clear and distinct").

v. Empirical certainty is immune to all doubt except universally convertible and reflexive doubts.

${ }^{23}$ Moore here assumes that knowing implies certainty. 


\section{The Domain of Sensory Autonomy}

Consider now the proposition that the liquid that Liz is drinking is orange juice, i.e., juice that is made from oranges. Certainly, there are universally available, technologically unassisted ways for Liz to form an opinion about this proposition. But these methods won't exclude the following doubt condition: that the liquid is a synthetic substance recently invented as a perfect substitute for orange juice. I'll call this the Fake O.J. scenario.

Consider the proposition:

1. The liquid that Liz is drinking is real orange juice.

The Fake O.J. scenario is:

2. The liquid that Liz is drinking is a synthetic product that tastes, looks, smells, and feels just like orange juice.

Liz cannot rule 2 false, but it would undermine her reason for thinking that 1 is true. It might be held that 2 is a sceptical doubt, since Liz has no empirical reason to believe it. And 1 does indeed convert to many singular empirical propositions, such as:

3. The tumbler out of which Liz is drinking is made of real glass.

The doubt condition for 3 is:

4. The tumbler is made of a solid that looks and feels just like real glass.

Liz cannot rule 4 false, but it would undermine any sensory reason she might have to believe 3. Moreover, since 4 is no less credible than 2 given Liz's epistemic position, the doubt condition for 1 converts to 3 . However, and this is the crucial point, the doubt condition for 1 does not convert to:

5. The liquid that Liz is drinking tastes, looks, smells, and feels just like orange juice.

Given full sensory exploration, Liz can achieve empirical certainty regarding 5, which attributes a complex appearance to the liquid she is drinking. There is no 
doubt condition for it akin to 2 . This difference between 1 and 5 is crucial to my argument. 5 attributes a sensory property to the liquid. 1 attributes a non-sensory material-composition property to the liquid. ${ }^{24}$

My claim is that properties that can be fully explored form a privileged subset about which empirical certainty is possible. I claim that it is possible to have empirical certainty only about these properties. Unfortunately, this does not allow us to distinguish sensory from non-sensory properties tout court. For it is not possible to achieve empirical certainty about all sensory qualities: as I showed in section III above, there are qualities that can be experienced, but not fully explored, and we cannot achieve empirical certainty with respect to these. Nonetheless, it is an important point, because it demarcates an area within which the senses are autonomous. Since the credibility of full sensory exploration cannot be increased by non-sensory knowledge, full sensory exploration cannot be helped by such knowledge.

Now, the point that I have just made runs contrary to a discussion by Jonathan Bennett (1965). ${ }^{25}$ For Bennett implicitly denies that what I have called empirical certainty is achievable in the realm of secondary qualities. Bennett's point rides on a conception of the epistemic relevance of colour-blindness that I rejected at the end of section III. He imagines a subject who is unable to distinguish between red and white, with the consequence that a red and a white object look the same to him. He may never discover his error, Bennett says:

A failure of secondary-quality discrimination ... [can] persist unsuspected through any variations in distance or angle of view, light-conditions, mouth-washing, cold-curing, and so on. (11)

${ }^{24}$ Origin properties and causal properties are other examples of properties regarding which we cannot achieve empirical certainty.

25 Bennett does not treat systematically of sensory exploration, or recognize it as an epistemically primitive means of gaining knowledge through the senses. But he does recognize, perhaps more clearly than many others, that one can observe an object under manipulation in order to test what one is inclined to believe on the basis of casual observation. 
By contrast, he says, a size-blind person, to whom to a mug and a cup of unequal size look the same, would quickly discover his error by placing the cup inside the mug and by other such manipulations.

Now, I do not think that this is right, at least not for the reason given. For I think, first of all, that colour-blind subjects have their own colour-palettes, and that their judgements are correct with respect to their impoverished spectra. The subject imagined would not sense red or white, but would have a colour $C$ that encompassed red and white. Red things and white things would both look $C$ to him. And he would sense both red objects and white objects as $C$-which would be correct. Also, as Bennett realizes, there is a range of exploratory manipulations with regard to colour, which would afford this subject empirical certainty that the two objects he is viewing are indeed $C$.

Bennett, however, makes a more general point that is of relevance here. Phenol-thio-urea is intensely bitter to about $3 / 4$ of all humans, he tells us, and tasteless to the rest. What if a dictator were to breed the "non-tasters"? When these non-tasters constituted the entire population, phenol-thio-urea would become tasteless. This shows how "a thing may change in respect of its secondary qualities without changing its primary qualities" (ibid, 9). Secondary qualities depend on the kind of experience their bearers create in subjects.

Returning now to colour, there are two views. The first is that it is a primary quality revealed (or denoted) by sensory experience (Jackson and Pargetter 1987, Matthen 2005): for example, spectral reflectance. The other view is that it is a secondary quality, as Bennett thinks. If it is a secondary quality, then we can arrive at empirical certainty with regard to whether an object possesses it. In this respect, it would be just like bitterness or tastelessness. One may not be able to tell whether or not something is orange relative to another perceiver, but one can be certain that it is orange to oneself. (This is essentially the same point as was made two paragraphs ago about the person who was unable to distinguish red from white.) 
But now, suppose the primary quality view is correct. Then, would sensory exploration entitle us to certainty about colour? There is a range of manipulations regarding colour, which could be used to ascertain whether or not something was orange. However, if colour were a primary quality, then the Benjamin Moore argument that I ridiculed in section I would regain its force. For then it should be at least metaphysically possible to make a paint that replicated the look of orange, even though it is, in fact, red-in the sense that it has the primary quality that is revealed by the sensory experience as of orange. Perhaps the paint would have the spectral reflectance of orange things, but send signals to the eye that made it look orange.

The point can be made in the following alternative way. In Hilary Putnam's famous Twin Earth example, XYZ plays exactly the same role as water does on Earth: it looks, feels, tastes, and smells just like water (and occurs in rain, lakes, etc.). Can we similarly imagine that on Twin Earth, things look exactly the same as orange things do on Earth, but are not orange. On a secondary quality view, this makes no sense (cf. Boghossian and Velleman 1989)-something that looks orange in all circumstances is orange. However, if colour is a reflectance or some other such primary quality, then it is coherent to suppose that things on Twin Earth should be of exactly that reflectance, but look red. But if this is so, the proposed distinction between sensory and non-sensory properties will fail.

The argument just given is good. It leaves me with two options. The first is simply to allow that colours are secondary qualities. For various reasons that I will not discuss here, I find this an unattractive option. The other is to distinguish between orange and the look of orange. I could say that the look of orange is distinct from being orange. This is a proposal very similar to that of Sydney Shoemaker (1994), who says that, in addition to colours such as orange, there is the property of looking orange, which Shoemaker calls an "appearance property". The difference is that Shoemaker thinks that things have the property of looking orange only when they create a visual appearance as of orange-i.e., when they are experienced as orange. By contrast, I would want looking orange to be a property that is discovered 
under sensory exploration. Thus, I would want to make it a part of looking orange that when an object with this property is placed in a vivid red surround, it will be experienced as yellow. My claim is that looking orange under exploration is a sensory property, and on the primary quality view, orange is not.

\section{Conclusion}

I have argued for the following:

1. Sensory exploration is a primitive form of knowledge gathering by the senses distinct from sensory experience.

2. Sensory exploration leads in the limit to a situation in which additional sensory evidence adds no credibility. I call this consilience.

3. Sceptical doubt is defined in terms of convertibility of a doubt condition.

4. Reflexive doubt is doubt about the subject's own epistemic position.

5. When consilience is achieved, the subject has a reason for belief that can only be weakened or defeated by sceptical or reflexive doubt-conditions.

The idea of sensory exploration is important even in domains where it does not lead to empirical certainty. I suspect, for example, that much laboratory observation employs exploration, not bare experience. And possibly it generalizes to a notion of demotic investigation: low-tech methods that include counting, measuring, estimating, attention to testimony, and so on. But these are all issues to be taken up elsewhere. 


\section{REFERENCES}

Auvray, Malika, \& Spence, Charles (2007) “The Multisensory Perception of Flavor," Consciousness and Cognition, doi:10.1016/j.concog.2007.06.005.

Bayne, Tim (2011) “The Sense of Agency," in F. Macpherson (ed.) The Senses Oxford: Oxford University Press.

Bennett, Jonathan (1965) "Substance, Reality, and Primary Qualities," American Philosophical Quarterly 2: 1-17.

Boghossian, Paul and David Velleman (1989) "Colour as a Secondary Property," Mind 98: 81-103.

BonJour, Lawrence (1985) The Structure of Empirical Knowledge Cambridge MA: Harvard University Press.

Broackes, Justin (2010) "How Do Things Look to the Color-Blind," in J. Cohen and M. Matthen (eds) Color Ontology and Color Science Cambridge MA: MIT Press: 291-405.

Burge, Tyler (2003) “Perceptual Entitlement," Philosophy and Phenomenological Research 67: 503-548.

Burge, Tyler (2010) Origins of Objectivity. Oxford: Clarendon Press.

Cohen, Jonathan (2009) The Red and the Real: An Essay on Color Ontology Oxford: Clarendon Press.

Føllesdal, Dagfinn (2005) “Ultimate Justification in Husserl and Wittgenstein,” in M. E. Reicher, J. C. Marek (Eds.), Experience and Analysis: Proceedings of the 27th Wittgenstein Symposium 2004 (Vienna: ÖBV\&HPT): 127-142.

Fulkerson, Matthew (2010) “The Sense of Touch," PhD Dissertation, University of Toronto.

Gibson, Eleanor J (1988) "Exploratory Behavior in the Development of Perceiving, Acting, and the Acquiring of Knowledge," Annual Review of Psychology 39: 141. 
Gibson, J. J. (1962) "Observations on Active Touch," Psychological Review 69: 477491.

Gibson, J. J. (1966) The Senses Considered as Perceptual Systems. Boston: Houghton, Mifflin.

Goldman, Alvin (1976) "Discrimination and Perceptual Knowledge," Journal of Philosophy 73: 771-791.

Hardin, C. L. (1988) Color for Philosophers: Unweaving the Rainbow Indianapolis: Hackett.

Hinkle, Nancy C. (2011) "Ekbom Syndrome: A Delusional Condition of 'Bugs in the Skin'," Current Psychiatry Reports Online First. DOI 10.1007/s11920-0110188-0.

Husserl, Edmund (1913/1976) Ideas Pertaining to a Pure Phenomenology and a Phenomenological Philosophy (first book) (tr. F. Kersten) Dordrecht: Kluwer.

Jackson, Frank and Robert Pargetter (1987) “An Objectivist's Guide to Subjectivism About Colour," Revue Internationale de Philosophie 41: 127-141.

Matthen, Mohan (2005) Seeing, Doing, and Knowing: A Philosophical Theory of Sense Perception Oxford: Clarendon Press.

Moore, G. E. (1959) "Certainty," in Philosophical Papers (London: George Allen and Unwin):

Pollock, John (1974) Knowledge and Justification Princeton: Princeton University Press.

Pryor, James (2000) “The Skeptic and the Dogmatist,” Noûs 34: 517-549.

Reed, Baron (2008) "Certainty", in Edward N. Zalta (ed.),The Stanford Encyclopedia of Philosophy (Fall 2008 Edition): $<$ http://plato.stanford.edu/archives/fall2008/entries/certainty/>.

Sacks, Oliver (1998) The Island of the Colorblind New York: Vintage Books, Random House. 
Segal, Gabriel (2007) "Poverty of Stimulus Arguments Concerning Language and Folk Psychology," in P. Carruthers, S. Laurence, and S. Stich (eds) The Innate Mind vol 3 New York: Oxford University Press: 90-105.

Shoemaker, Sydney (1994) “Phenomenal Character,” Noûs 28: 21-38.

Spelke, Elizabeth (2000) “Core Knowledge,” American Psychologist 55: 1233-1243.

Wittgenstein, Ludwig (1977) On Certainty (tr. D. Paul and G. E. Anscombe) Oxford: Blackwell. 